Journal of Engineering Science and Technology Review 5 (3) (2012) 32-34

Special Issue on Simulation of Manufacturing Technologies
JOURNAL OF

Engineering Science and

Technology Review

Research Article

\title{
On the Application of an Optical-Acoustic Method to Study Fracture Processes During Linear Friction Welding
}

\author{
A.A. Girfanova, Y.I. Nasedkina, V.V. Astanin, I.V. Alexandrov and F.F. Musin
}

Ufa State Aviation Technical University, K.Marx str. 12, Ufa, 450000 Russia

Received 1 August 2012; Accepted 25 August 2012

\begin{abstract}
The paper presents the results of the application of a newly developed method to study deformation and fracture processes in specimens produced by linear friction welding. This method combines mathematical modeling and experimental mechanical testing. By application of this method it has been demonstrated that during uniaxial testing of welded joint specimens of Ti-6Al-4V and Ti-6Al-3.5Mo shear bands occur at an angle of $45^{\circ}$. Fracture of the specimen took place near the weld line, in the heat-affected zone, of the Ti-6Al-4V alloy. Microcracks started in the centre of the tested specimen. Recording of acoustic emission signals during tensile testing identifies the appearance of the initial microcracks and can predict the precise moment of fracture.
\end{abstract}

Keywords: optical system VIC-3D; acoustic emission; quality control; linear friction welding; fractographic studies.

\section{Introduction}

The ability to predict and improve the reliability of complex structures for aircraft applications, such as hollow blades or bladed disks (Blisks), is connected to the investigation of strain distribution and the stress-strain state of structural members. Such investigations can be carried out by combining mathematical modeling and experiments. One of the experimental methods which is proposed in this paper is the mechanical testing with synchronous recording of strain fields using the optical system VIC-3D and of acoustic emission (AE) signals. The proposed combined method can be used effectively to monitor strain changes and localization, and to perform quality control on innovative products, such as designing new generation aircraft engines.

The present paper presents the results of the development of such an application of a combined method of study of deformation and fracture processes in specimens produced by linear friction welding.

\section{Material for study and research procedure}

Welded specimens were produced by linear friction welding (LFW) dissimilar specimens of two alloys, Ti-6Al-4V and Ti-6Al-3.5Mo [1]. An example of the microstructure is shown in fig. 1 . The tensile test specimens were sectioned from the welded joints, with a cross section of $15 \times 0.8 \mathrm{~mm}$ (fig. 2). The welding plane is perpendicular to the direction of application of tension. The uniaxial tensile testing of specimens was conducted using an INSTRON 5982 machine with a crosshead speed of $1 \mathrm{~mm} / \mathrm{min}$. The AE signals were

\footnotetext{
*E-mail address: girfeek@yandex.ru

ISSN: 1791-2377 @ 2012 Kavala Institute of Technology. All rights reserved.
}

recorded using the MALAKHIT AS-12A software and hardware system, and investigation of displacement and strains was performed using the Vic-3D digital optical system.

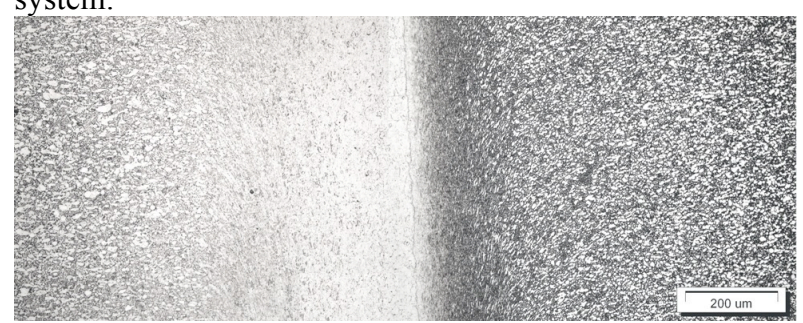

Fig. 1. Microstructure of the welded joint of Ti-6Al-3.5Mo (on the left) and Ti-6Al-4V (on the right)

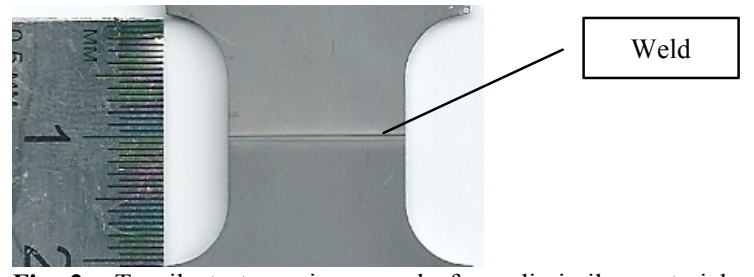

Fig. 2. Tensile test specimen made from dissimilar material welded joints

\section{Results}

Fig. 3 shows synchronized diagrams of tensile tests and $\mathrm{AE}$ signals of the welded joints. At the initial stage of the tensile load increase (0 to 100 seconds), the AE signals grow in amplitude which is typical of gripped specimens in such testing conditions. This is followed by a decline in signal intensity which is related to the deformation of the tensile test specimen. 


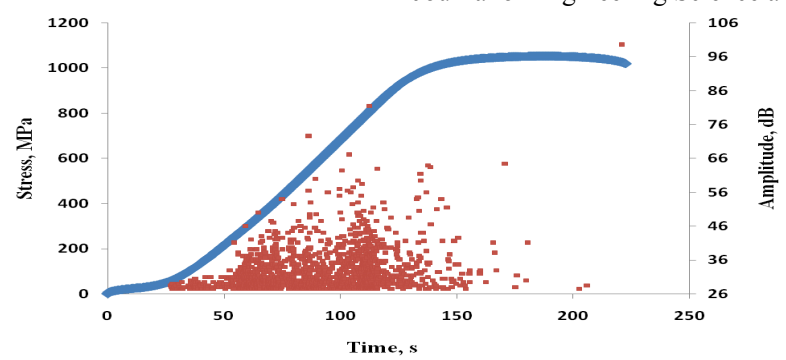

Fig.3. Superposed synchronized diagrams of tensile tests and AE signals

At $t_{1}=140 \mathrm{~s}$ elastic strain is gradually concentrating near the specimen corners (fig.4 (a)), where microcracks at the surface appear, and produce AE signals with an amplitude of up to $70 \mathrm{~dB}$.

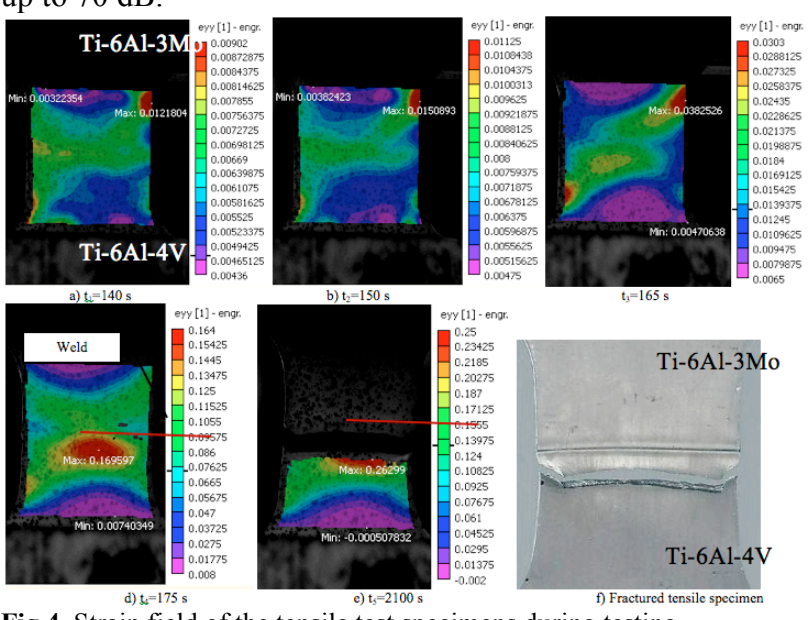

Fig.4. Strain field of the tensile test specimens during testing

When plastic strains develops in the time interval from 145 to 160 seconds, shear bands at $45^{\circ}$ form in the specimen (fig.4(b)). It can be seen in fig. 4(c) that in the welding line area there are high strains, as microstructure and texture of the welded joint and its adjacent area are different from base metal. There is a decline of the acoustic signals activity at this stage, which is related to the arrest of the formation of surface microcracks as stresses relax in other parts of the specimen [2].

After $t_{4}=175 \mathrm{~s}$ (fig.4(d)), strain distribution becomes much more complex, with a second shear band appearing, and forming a cross together with the previous shear band. Intersection of these two shear bands affects stresses and leads to the creation of further microcracks in the centre part of the specimen. The formation of these microcracks is registered with AE signals.

Microcracks join together to form a large crack that extends from the center of the cross of the shear bands to the edges of the specimen. This final crack which is responsible for the fracture of the specimen does not originate from the weld line but from the point where the two shear bands cross. This sequence of events is confirmed by fractographic studies. In the middle of the specimen (fig.5(a)) evidence of breaking is visible, which is the result of the first microcrack forming. The other parts of the specimen fractured demonstrate a cleavage (fig.5(b)) characteristic of monotonic crack propagation and fracture indicating a ductile fracture. The crack itself has rather smooth edges. The structure of the specimen at the edges differs from the one in the middle.

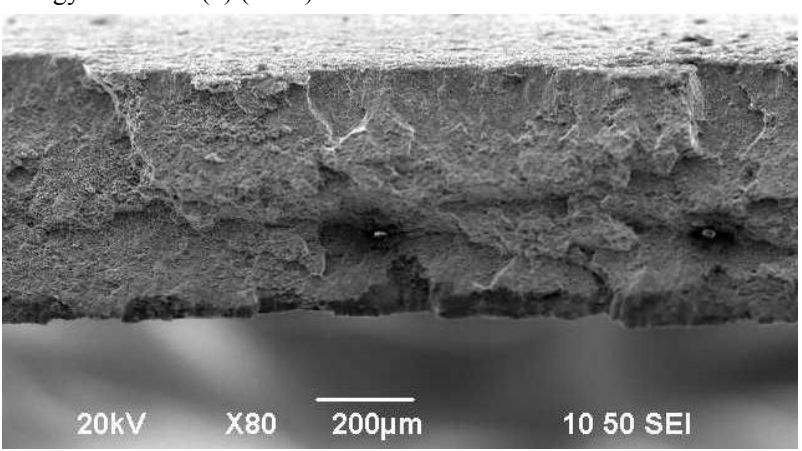

a)

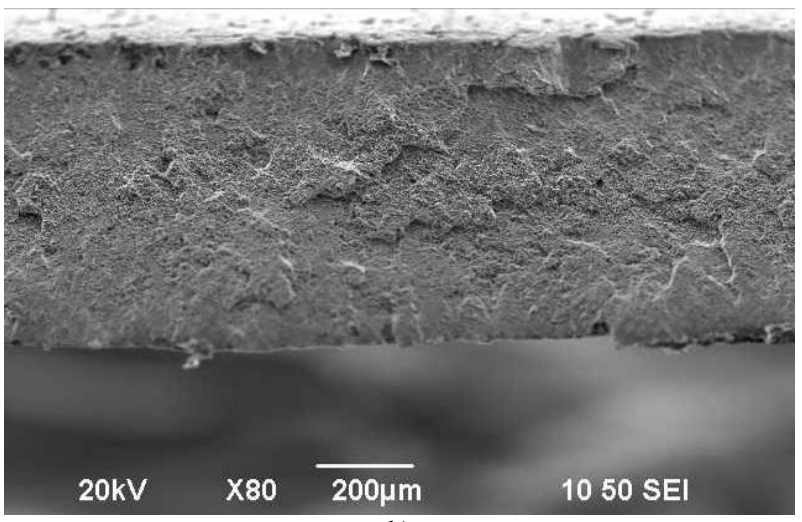

b)

Fig.5. Fracture surface in the centre (a) and edges (b) of the specimen

It should be noted that there are shear bands present in all fractured specimens, while in the AE signals recorded one can identify the various stages of plastic straining and start of fracture. By constructing a sketch of strain distribution in the specimen together with data of the amplitudes and energies of $\mathrm{AE}$ it is possible to predict, with a sufficient degree of certainty, the position and the cause of fracture long before the specimen or the structure fractures.

\section{Conclusions}

The application of this combined approach has identified the mode of strain concentration during uniaxial testing of welded joint specimens of Ti-6Al-4V and Ti-6Al-3.5Mo which had been produced by LFW. It has been shown that shear bands occur at an angle of $45^{\circ}$. Fracture of the specimen took place near the weld line in the heat-affected zone in the Ti-6Al-4V alloy. Microcracks started in the centre of the tested specimen. Recording of AE signals during tensile testing identifies the appearance of the initial microcracks and can predict the precise moment of fracture.

\section{Acknowledgements}

This work is part of the project "The Technology and Manufacturing/Industrial Production of the Mounts/Components and Vanes/Blades of Gas-Turbine Engines with Lightweight/Reduced High-Strength Constructions for Aircraft Engines of New Generation", conducted within the Federal Target Program according to the RF Government Regulation №218 from April, the $9^{\text {th }}$, 2010, "About the measures of State support for development of co-operation of Russian higher education establishments and organizations, realizing the complex projects in developing high-quality production". 
A.A. Girfanova, Y.I. Nasedkina, V.V. Astanin, I.V. Alexandrov and F.F. Musin/

Journal of Engineering Science and Technology Review 5 (3) (2012) 32-34

\section{References}

1. Karavayeva M.V, Kiseleva S.K., Bychkov V.M., Medvedev A.Yu., Supov A.V., Vusin F.F., Alexandrov I.V., Latysh V.V. The effect of the amount of upsetting on formation of a welded joint during linear friction welding. Letters on Materials. 2 , 40 (2012).
2. Yermolov I.N. Non-destructive testing. In 5 books. Book 2. Acoustic H44 methods of testing: Practical guide/ I.N. Yermolov, N.P. Alyoshin, A.I. Potapov; Edited by V. V. Sukhorukov.- Moscow: Vysshaya shkola, 1991.- 283 p. 